\title{
UNDERSTAND THE VALUE CHAIN NETWORK, UNDERSTAND THE MARKET, UNDERSTAND THE INDUSTRY AND UNDERSTAND THE CUSTOMER
}

\author{
DAVID WALTERS \\ d.walters@itls.usyd.edu.au \\ Institute of Transport and Logistics Studies \\ University of Sydney
}

\begin{abstract}
Supply chain management is under pressure as many organisations use it as a means of producing cash through cost-efficiency programmes (Walters and Rainbird: 2007). This paper discusses the increasing application of a value chain network approach, one that uses network management and the assumption that "customer centricity" replaces efficiency decisions with effectiveness decisions and in doing so results in improved marketing and financial performance. This paper uses examples from a wide range of organisations and industries to illustrate the increasing application of the concept.
\end{abstract}

\section{INTRODUCTION}

There are an increasing number of contributions to the value chain network literature. Flint (2008) argues that value management begins with understanding that value is based upon customer perceptions and is not inherent in any product, service or system. Furthermore the "customer" is the next person in the next value chain process within the organisation, the next business unit to whom you deliver, the immediate paying customer be it another business unit or an external firm and the subsequent downstream organisations and consumers through to the final end-user. Flint suggests that world-class companies often think of their suppliers also as customers, and ask how suppliers and suppliers' suppliers may be better serviced. This suggests that every link in a value chain network constitutes a supplier-customer relationship.

Flint argues that a significant amount of research states that all customers value functional benefits, relational benefits, service benefits and brand reputation (quality, consistency) - and they evaluate each distinctly. Customers also evaluate both the monetary and nonmonetary costs of doing business with a vendor and that they must incur acquisition costs to obtain those benefits. Accordingly, we should identify and expend effort on those activities that improve the opportunity for a customer to experience an improved, very specific, desired benefit. Creating value means constantly identifying the value expectations, and the subsequent perceptions, of customers. In exchange, customers are often willing to pay 
suppliers more in terms of price, volume, share of business, and share of mind, improving the value that suppliers receive from customers all the way back through the value chain.

Furthermore: "Moving (creating) value recognises the fact that most of what and how customers make value judgments is out of the control of marketers/suppliers/brand managers. Customers constantly are bombarded with buying-related information. As customers, regardless of definition, go about living their lives, they are constantly refining their interpretations about the value of specific products, services, and relationships. Since brand managers/suppliers have little influence on this valuing process, they are forced to be constantly vigilant to the changes in what specific customers value and why. It is nothing short of an entirely different way of looking at customers and supply chain relationships."

Essentially this is the argument put forward by Slywotzky and Morrison (1997). They suggest customers throughout a value chain have value drivers, their buying imperatives, the product-service attributes that are critical to their purchase situation outcome. The issue for management is to identify what, where and how within the value chain network this value can be produced to create mutual value. Flint identifies some other interesting issues. For example, he suggests that most critical aspects of value propositions are changing very rapidly citing the consumer electronics giants, LG and Sony, for whom constant change means rapidly increasing technological capabilities and changing customer expectations within a world of changes - and that to make one wrong strategic move based on an inaccurate or incomplete evaluation of value movement could result in a firm playing catchup for years as witnessed by Dell's operations in China.

Much of Flint's commentary is based upon "relationship management". He provides the example of Samsung who focused on quality metrics but ignored "emotional bonding" through superior brand management. He suggests Samsung has significantly improved its ability to increase value creation throughout its supply chain, both for business customers and consumers. However, it has yet to create the powerful emotional bonds that solidify customer relationships and facilitate higher margins that its tougher competitors have, suggesting "quality alone is never enough".

For Flint, developing relationships enable significant and frequent information sharing through joint processes that involve multiple supply chain partners. He cites IKEA as an example. The company has long been known for its ability to create value for both suppliers and end-user customers by integrating demand and supplier response processes and designing supply chains that make it easier, more affordable, and in many cases, more enjoyable for customers to acquire the benefits they want: "They not only execute superior supply chain management, they also win advertising awards for the creativity and effectiveness of their marketing communications. They have a clear-focus on specific target 
markets, know how to own their position within those markets, and stay at the forefront of changing value expectations - some of which they drive themselves." He closes with: "Value must be experienced at each and every step of the supply chain (value chain network?) within and outside of your organisation. Your targets are moving too quickly in today's global business environment. You must constantly move the value bar higher at every link you can influence and keep up with changes that you cannot influence but to which you must respond - all ahead of the competition." The question to be answered is: how?

\section{RESEARCH STRATEGY}

\section{Value chains and value networks}

There is an extensive literature building that deals with network-based business models. While much of this is concerned with the developing theory and concepts some applications studies have been appearing, mostly in the fringe academic publications of major consulting organisations and the business pages of the national and international press. The examples used in this paper have been collected from business reports and conferences; in aggregate they indicate an increasing number of applications of the value chain network concept across a wide range of industries.

\section{Questioning the supply chain: The emergence of demand chain thinking}

Supply chain management supporters have argued that that the supply chain has attempted to meet all the changes identified within the new economy. Supply chain management has focused on moving products and services downstream towards the customer. Typically the supply chain is coordinated by manufacturing companies or dominant resellers who use in-house manufacturing and distribution facilities to achieve market-based objectives such as market share volumes and customer penetration. Demand chain management changes the emphasis towards "customisation", responding to product and service opportunities offered by specific customers or customer groups sharing particular characteristics. The preference is to outsource rather than own the functions and processes that facilitate and deliver value. Focus is on asset leverage and communication through distributed assets and outsourcing. There is a large incentive to integrate supply and demand chains - it provides new opportunities for creating (or adding extra) market value. Working both together results in more specific and manageable value propositions and increases the returns to the valuechain participants. There is an interdependent relationship between supply and demand: companies need to understand customer demand before they can manage it, create future demand and, of course, meet the level of desired customer satisfaction. Demand defines the supply-chain target, while supply-side capabilities support, shape and sustain demand.

Tierney (2003) quoting Lee depicted a triangle with customer demand at the pinnacle and supply chain and demand chain management at the bases. He cites the success of 7-Eleven 
Japan, whose stock prices continued to increase despite Japan's recession for the past 10 years. The secret of its success is demand-led management, which led it to identify sales patterns and customer preferences and to match those by re-engineering its category management and store product layouts resulting in increased sales and profitability. They emphasise the point that demand chain management attempts to analyse and understand overall demand for markets within the firm's current and potential product range. Supply chains, by contrast, emphasise the efficiencies in the production and logistics processes, while the demand chain emphasises effectiveness in the business. A very useful point in their argument is that demand chain analysis and management helps to improve an organisation's processes by aligning the organisation around a common plan, improves coordination within the supply chain by using forecasts and plans, and exploits the commercial processes by understanding consumer demand and by selecting those markets that best meet an organisation's (owned and/or "leased") skills and resources.

This introduces the notion that an effective approach to operations management is through demand chain management. It first requires the organisation to understand its current and potential markets and second to identify the essential (or core) processes and capabilities that are required for success. Godsell, Harrison, Emberson and Storey (2006) take the debate yet further by pursuing a demand strategy model that comprises a marketing component - demand definition and creation - and also a supply chain component demand fulfilment. Their approach offers an integrated demand chain/supply chain with a number of activities.

(1) Demand chain objectives are based upon the organisational needs to address revenue generation and cost reduction holistically. A market strategy (2) identifies a "relevant basis for segmentation that is meaningful not only to sales and marketing but also to the supply chain." This is followed by (3) linking market strategy to supply chain process strategy, whereby appropriate supply chain strategy processes are aligned with customer value drivers; it is influenced by patterns of demand flow and the extent of customisation. Process enablers (4) facilitate implementation of the supply chain process. These are suggested to be organisational design, a performance management system that measures and motivates individual and organisational activities, and relevant information systems that drive the overall process.

Mentzer (2006) assumes a similar role for demand chain management. He argues that demand management is the creation, across the supply chain of a coordinated flow of demand. Marketing should create demand opportunities for various products but promotional activities are often not shared with other stakeholders be they intra- or inter-organisational partners. Mentzer suggests that the role of demand management may well be to decrease demand because the opportunity that has been identified cannot be met profitably. Demand 
management should assess the profit (and cash flow impact?) of alternative products and customers referring to capability and capacity constraints. In terms of the current "push" and "pull" strategies, "pull" activities are emphasised where capabilities and capacity exists and lessened where they are constrained.

Mentzer is also suggesting another role for demand management - the relationship management aspects of supply chain management. Here the suggestion is that demand management is well suited to working with both downstream partners to agree performance measures (and rewards) butalso to coordinate a matching process in which inter-organisational capabilities and capacities are coordinated in an attempt at achieving optimal market and financial performance. Mentzer discusses the interrelationships between sales forecasts and demand suggesting that a sales forecast projects the future of expected demand given a stated set of environmental demands and organisational capabilities and capacities.

The organisation's response is an operational plan that details response processes and plans designed to meet the sales forecast through the implementation of procurement, production and logistics plans. He makes a significant point by suggesting that sales force remuneration should be geared to the capacity and capability constraints detailed by the operational plan.

It is becoming increasingly apparent that supply chain coordination is not efficient without an adequate understanding of demand; the issue for management is how best to address the problem. Godsell et al op cit suggest this be achieved by defining "demand chain objectives that align with the relevant business unit strategy"; while it is claimed that "these objectives provide all employees in the demand chain with an aligned set of objectives and measures". It also assumes the strategies are relevant. Perhaps their model would benefit from a "market opportunity analysis" process that explores the demand characteristics comprising opportunity on a more extensive scale. An important step is common to each of these contributions; it is to re-validate the notion of the demand chain as a separate entity from the supply chain.

Perhaps an example here will help. Dell Computers operate a demand-led customer response supply chain. Their business model is an example of Bucklin's postponement (as opposed to speculation) channel model of some years ago. The Dell model reflects the emphasis on financial performance as a criterion and as such the Dell business model is very cash effective. Stank and Mentzer (2007) describe DSI (Demand and Supply Integration), an approach by Dell that enables (and empowers) customer service representatives to access sales, marketing and supply chain information to resolve problems that occur when specific (ordered) components are unavailable by offering customers alternatives at acceptable incremental prices. DSI has been developed from an integrated sales and operations 
planning process, in which operational plans link procurement, manufacturing, distribution, finance and human resource plans. A demand plan determines what should be marketed and sold and when - given the supply capabilities and constraints of the organisation. Demand plans may involve suppressing demand when availability of components is constrained, placing marketing emphasis on products where inventory levels are exceeding limits, or shifting demand towards higher margin products. By integrating demand and supply (DSI) we create a more powerful model - the value chain network.

\section{Positioning in the value chain network}

Some companies are learning how to take a creative approach to mobilising resources by identifying specific locations within the value chain network where their specialist contributions can add value for the entire network. Bruce Grey (MD, the Bishop Technology Group) (2006) discusses the holistic value chain network business model from a resource management perspective. He argues that rigid resource-based systems, typically highly automated factories operating with rigid and standardised processes that apply resources to specific places at predetermined times, are becoming obsolete. Grey's argument is that "resource mobilisation" (the increasing externalisation of tasks and a corresponding increase in cooperative arrangements or networking) is the necessary response to fragmenting less predictable demand. Grey illustrated his argument by citing a McKinsey Quarterly article describing Li and Fung, a Hong Kong-based value chain network coordinator that works with some 7500 partner organisations in 37 countries manufacturing a range of apparel products from high quality woollen sweaters to synthetic slacks: Li and Fung sit at the hub of a network of specialist enterprises that mobilise resources in different combinations depending upon the rapidly changing demand and coordinate a response. Vatne (1995) provides another example reporting a Scandinavian empirical study of the internationalisation of SMEs, their use of external resources, and in what sense local resources are mobilised in the process of internationalisation.

Another model finding support is the original-design manufacturer (ODM), a model that is based upon product innovation. Taiwan's Compal and Quanta Computer offer equally compelling examples of distributed product innovation. These ODMs creatively pull together highly specialised component and subsystem suppliers in order to generate ideas for delivering higher performance at lower cost in a broad range of digital devices, including digital still cameras, mobile telephones and notebook computers. Instead of designing products in detail from the top down, ODMs specify ambitious performance targets and then rely on this diverse network of technology partners to find new ways of meeting them. It has been suggested that the recently introduced iPhone by Apple follows this principle.

There are other examples; companies such as Eli Lilly, Nokia and Procter \& Gamble (P\&G) are also deploying informal open-innovation techniques. In 2001, for example, Lilly created a wholly owned subsidiary - InnoCentive - that has recruited a distributed network of more 
than 80000 research participants (called "solvers"), in over 170 countries, to help its clients find solutions to difficult R\&D challenges. InnoCentive has more than 30 such clients (called "seekers"), including Dow Chemical, P\&G and its own parent, Lilly. When seekers confront a particularly difficult research challenge, they post their requirements to InnoCentive's solver network and offer a bounty to anyone who finds a solution. InnoCentive's success rate is roughly 50 per cent - not bad for research problems that the seekers' internal R\&D staffs couldn't handle. Most interesting of all, InnoCentive's solver network is beginning to self-organise, with diverse solvers coming together to address a specific seeker's needs. This is a classic pull system: when needs can't be easily determined in advance, companies can create platforms to mobilise distributed resources readily.

This approach does not infer that the final output of the mobilised resources model is a highly customised, unique product; it is suggesting that customer satisfaction can be more closely achieved by using product and process platforms as modular systems that can be combined in a number of ways to meet end-user demand. Examples of product platforms are seen in the automotive industry where platform components are shared on an intra- and inter-organisational base. Examples of process platforms are seen in Internet merchandisers such as Amazon and e-Bay. Recent changes in Australian manufacturing/operations reflect these changes. Lloyd (2007) reports on a dramatic shift in the type of business now becoming successful in areas that were once dominated by "high volume - low value" manufacturing such as textiles (apparel and footwear) which are now being replaced by food processing, advanced aero space, pharmaceuticals and medical devices.

The examples above (Roberts, 2006; Lloyd, 2007) indicate the directions in which a number of Australian organisations are moving. They are identifying their capabilities, and where they "fit" within an industry value chain network, and are achieving market and financial success. The Bishops Technology Group collaborates with partners across the world to develop innovative products. Grey, Bishop's CEO (2006) suggests that an important facet of this activity is the relative ease with which information that flows between ODMs, suppliers, logistics providers, distributors, wholesalers and retailers can be captured providing valuable input about the efficacy of product design, and distributor and customer response. This suggests there is a mutual understanding of the value chain network as a viable business model by its members; more than that is the fact that they understand how value can be created or enhanced by using this knowledge of the aggregate processes and capabilities, and even how its assets in the network can be leveraged by the stakeholder membership to achieve this objective. Jay (2008) reports on two other successful Australian companies that have identified exclusive value chain network positions: GKN Aerospace Engineering Services has designed more than 1000 parts for the Lockheed-Martin F-35 Lightning II Joint Strike Fighter; another, Peregrine Australia, makes a radio-frequency sapphire wafer chip for "top-end" mobile phones. 
A number of questions should be asked: What is it that contributes to the success of these companies? What processes do they follow? And how is success measured? Clearly there are a number of contributory factors but one they do share is that they do understand the philosophy of the value chain approach and plan to participate within the value chain network at the point that they can contribute most to the network stakeholders.

Figure 1 serves to remind us of the fundamental concept underlying the value chain network - value is seen as a stakeholder-based concept - the performance expectations of all participants must be met for the continued success of a value chain network; and this is achieved by integrating and coordinating the assets, processes and capabilities of the stakeholders to create an optimal value output, such that each stakeholder's resources receive satisfactory returns. Figure 1 identifies with Flint's emphasis on all aspects of relationship management, identifying there are both upstream and downstream partners, and the collaborative activities they undertake. It also introduces the business models that are increasingly common within value chain networks reflecting the transparency that has replaced the corporate secrecy of the traditional vertically integrated business model and the flexibility and agility that network structures are known for. This "new economy" approach has been accompanied by an exclusive vocabulary. Terms such as collaboration describe the overall willingness of organisations to seek and implement customer-based solutions using shared resources and producing shared benefits. Co-creativity, or prosumerism, is the involvement of consumers (and possibly that of distributors) in the design and development of product-services. Co-productivity is a more operational role by suppliers, distributors and customers in which they undertake tasks that hitherto were the role of other channel/ chain participants. Co-opetition describes the situation in which competitors work together to meet individual objectives using mutual facilities. Co-destiny is used to ascertain the extent to which members of a business coalition share the same objectives, strategies and values. Complementors are markets or market segments that offer opportunities to extend existing market opportunities or to enter entirely new markets. (This will be explored in detail later.) Value migration occurs as both economic and shareholder value flow away from obsolescent (and obsolete) business models; it is the shift of business designs away from outmoded designs toward others that are better designed to maximise utility (value) for customers and profit for the company. Interpreneurship refers to the management expertise required to identify the opportunities to introduce new (and alternative) business models and processes into new and existing markets. Again a question must be asked: given the range of alternative structures, how do the network members identify their role in the value delivery process and, more importantly, how do they decide upon specific aspects of the value process as their contributions? 
Co-opetition

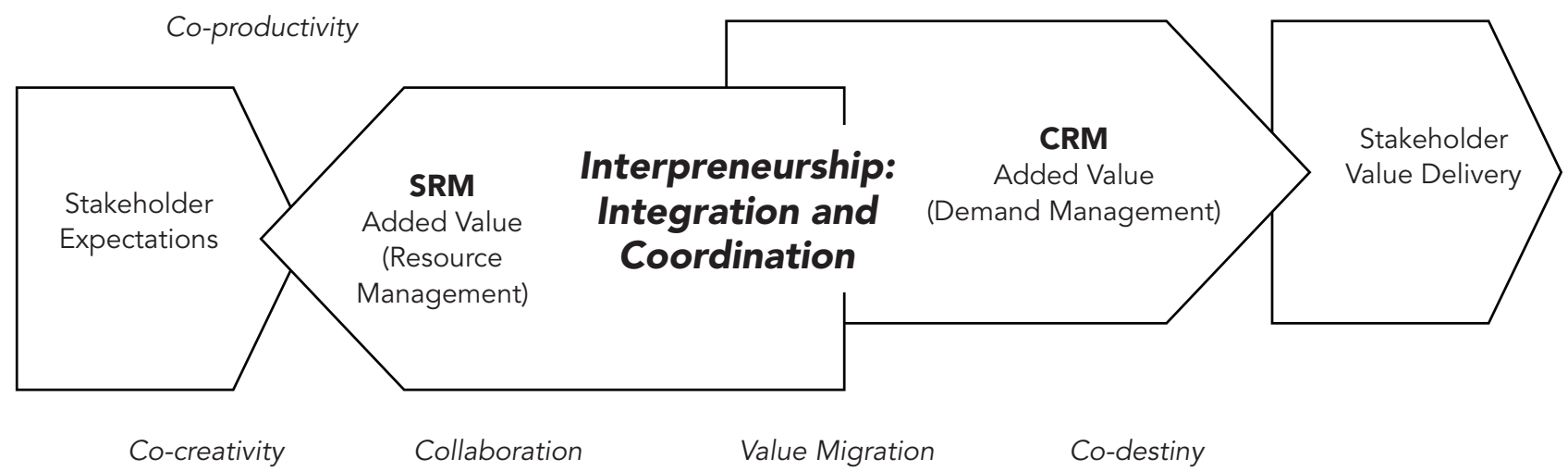

Figure 1: A value chain network-based business model

Flint op cit is of the opinion that "customers, regardless of definition, go about living their lives, they are constantly refining their interpretations about the value of specific products, services, and relationships" - accepting that there will be ongoing changes to customer expectations. A "free-flow" of information concerning these changes is an essential feature of the value chain network. But this view, and those of Slywotzky and Morrison op cit, do identify a misunderstanding of the assumption concerning customer expectations that many marketing managers labour under - that the basis of almost all consumer choice can be related to pricing decisions by suppliers, and further, that this through its impact on profitability is a key influence that should be reflected throughout the value chain network. Fortunately there is evidence to suggest this to be erroneous.

\section{What is value?}

Anderson and Narus (1998) have argued that very few suppliers in business markets are able to answer questions concerning what value actually is, how it may be measured and what the suppliers' products (or services) are actually worth to customers. They comment:

\footnotetext{
"Customers - especially those whose costs are driven by what they purchase -increasingly look to purchasing as a way to increase profits and therefore pressure suppliers to reduce prices. To persuade customers to focus on total costs rather than simply on acquisition price, a supplier must have an accurate understanding of what it is customers value, and would value".
}

The authors suggest that the successful suppliers in business markets are successful because they have developed customer value models, which are data-driven representations of the worth, in monetary terms, of what the supplier is doing, or could do, for its customers. Customer value models are based on assessments of the costs and benefits of a given market offering in a particular customer application. Value is defined by Anderson and Narus, as follows: 
"Value in business markets is the worth in monetary terms of the technical, economic, service, and social benefits a customer company receives in exchange for the price it pays for a market offering."

Value is expressed in monetary terms. Benefits are net-benefits; any costs incurred by the customer in obtaining the desired benefits, except for the purchase price, are included. Value is what the customer gets in exchange for the price it pays. Anderson and Narus add an important perspective concerning a market offer. A market offer has two "... elemental characteristics: its value and its price. Thus raising or lowering the price of a market offering does not change the value such an offering provides to a customer". And, finally, value takes place within a competitive environment; even if no competitive alternatives exist, the customer always has the option of "making" the product rather than "buying" it.

The notion of a customer value model is not new. Heskett, Sasser Jr and Schlesinger (1997) propose a customer value equation which in addition to customer benefits and acquisition costs also includes process quality and price. The model is described by:

\begin{tabular}{|c|c|c|c|}
\hline \multicolumn{4}{|c|}{ Results produced (Value-in-Use) } \\
\hline Value & $\begin{aligned}= & \text { for the customer } \\
& \text { less }\end{aligned}$ & + & Process quality \\
\hline & $\begin{array}{l}\text { Price to the } \\
\text { customer }\end{array}$ & + & $\begin{array}{l}\text { Costs of acquiring } \\
\text { the product }\end{array}$ \\
\hline
\end{tabular}

In their model results produced for the customer are based upon results not products or services that produce results - the actual value benefits delivered.

Process quality had been described by Parasuraman, Zeithaml and Berry (1985) as:

- Dependability (did value provider do what was promised?)

- Responsiveness (was value provided in a "timely" manner?)

- Authority (did provider elicit a feeling of confidence in the purchaser during the delivery process?)

- Empathy (was a customer view taken?)

- Tangible evidence (was evidence left that the value was delivered?)

Price, observes Heskett and his co-authors, is often used by both the customer and the supplier but clearly acquisition costs may be high, and possibly exceed price. The authors suggest that suppliers who can lower customer acquisition costs may be able to charge premium prices. This relationship has been used in value-based pricing where the life cycle costs of products are considered as an aspect of the total purchase (i.e. acquisition costs) and these, with price, are the value actually delivered. 


\section{Value-in-use and added value}

Another important element is an understanding of the purchasers' use of the product - the value realised - and MacMillan and McGrath (1997) suggest that competitive advantage may be realised if the consumption chain is identified. The authors claim that:

"a company has the opportunity to differentiate itself at every point where it comes into contact with its customers - from the moment customers realise they need a product or service to the time when they no longer want it and decide to dispose of it".

MacMillan and McGrath's consumption chain has an interesting and worthwhile application for strategic value chain decisions, particularly their implementation through the value chain. The technique identified - "all the steps through which customers pass from the time they first become aware of your product to the time when they finally have to dispose of it or discontinue using it" - describes the customer life cycle typically used in life cycle costing. The process considers a number of questions: awareness, availability, choice, purchasing procedures followed, product delivery installation, financing payment, storage, mobility, end-user uses, applications service, returns or exchanges, maintenance and disposal issues. Each of these activities creates cost for customers and, as such, need to be considered when the customer is making a purchase decision. Customer acquisition and life cycle costs must be deducted from the benefits delivered by the product or service to derive a measure of total delivered value. Added value occurs when a customer receives additional benefits, or reduced acquisition costs from transactions. A product-service that increases a customers' productivity (either by enhancing benefits or reducing acquisition costs) can be said to "add value".

The information provided by consumption chain mapping can be directly applied to value chain decisions. Two examples will illustrate the benefit of such an analysis. Ordering procedures are being revolutionised with Internet technology and, in the future, these may be automated as wireless technology is applied to both business-to-business and business-to-consumer markets, making reordering an automatic response to levels of use and inventory holding. The American Hospital Supply application of customer installations of computers to inventory management has been widely adopted over the years. The recent wireless technology developments are forecast to replace this technology with yet even more intelligent replenishment systems. Many value chain intermediaries are currently developing intelligent technology (using "Smart" technology); for example, home delivery activities of the large food retailers are considering "technology" that will link consumers' refrigerators with home delivery services.

In other applications remote diagnostics are used by Rolls Royce Aero Engines, Tandem Computers and Caterpillar Construction Equipment for identifying product component 
malfunctioning. This advance notice of failure allows early dispatch of replacement parts (thereby reducing field inventories and the alerting of technical staff (increased utilisation of human resources), both of which reduce costs for customers and the value chain. Current practice typically follows Figure 2, in which the lead taken by research-led design and development is shown. Caterpillar have identified an important customer value driver in the need to minimise downtime on construction projects (where the cost of equipment failure may cost "thousands of dollars" per day). As a result, the remote diagnostics equipment will identify problems with the equipment and electronically "give notice" of a pending problem and potential loss of equipment working time. This lead time is put to good use, replacement parts and technician availability are marshalled and the problem minimised if not resolved. This response is an example of using the value chain to create added value for customers simply by developing an understanding of end-user activities (and the problems they can encounter) and creating solutions. It is likely that Caterpillar customers (and endusers - usually not the same people) do not consider the additional price of this feature as it is insignificant compared with downtime costs!

- How and where and by whom will the product be "manufactured"?

- What are the product-service production format alternatives?

- Who will "deliver" the product?

- And how?

- How will the value be serviced and reinforced?

- What are the cost profile alternatives?

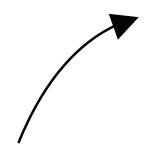

Questions

- What is the customer value to be delivered?

- What are the preferred product-service format alternatives?

- What are the assets, processes and capabilities required for success?

- What are the investment implications (capital, capacity, forecast utilisation?)

- Are they already available?

- Who owns them?

- Which of them are "core" to the market opportunity?

- What are the competitive issues?

- Are there enablers that are required?

- Do complementors exist?

Who "owns and manages" the processes and activities is a function of strategic effectiveness and operational efficiency 
Design and development is not only product-led; there are examples of process-led initiatives. For example, Tesco the UK retailer, researched customer "dislikes" and found that check-out queues were viewed negatively by customers; as a result a programme of staff multi-skilling training was undertaken. Staff were equipped with sufficient skills to meet the company objective of maintaining a minimum number of customers awaiting service. Another process-led example is given by Champy (2008) with MinuteClinic, a chain of healthcare service outlets that are based on the premise that many common ailments do not require treatment by a GP or specialist medical practitioners of hospital "emergency departments", but can be safely, inexpensively and rapidly handled by trained nursing staff. MinuteClinic kiosks are open seven days a week, are often located in specific stores or in shopping malls, and display the ailments that can be treated together with prices for consultations. Strict protocols (driven by software) are in place to confirm diagnoses, ensure referrals are made and ensure that treatment of serious conditions is not attempted. The service is supported by other software that advises on "best practice" and a druginteraction database. These examples illustrate the necessity of a complete understanding of the value chain structure and partners, both upstream and downstream. In an interesting article, Bun and Van Zijll Langhout (2008), identify the benefits of monitoring stakeholder interests and practices in the value chain network.

Becoming relevant in the value chain requires a shift from the traditional "push" market strategy to an innovative "pull" strategy (Brown \& Hagel, 2005). To achieve this endconsumer focus, a new and internal organisation may need to be established. Ideally it will have a management approach that extends well beyond the intra-organisational structures that typify many organisations and that identify and manage the new value chain position. Bun and Van Zijll Langhout (2008) suggest an approach: Step one involves the organisation in making contact with the target group (as has Intel) to make the brand visible for them and to make them understand the value benefits it contributes. Often this group will offer ideas to improve a specific situation in which the consumer and the brand are both involved. In step two the new relationship will be strengthened by extending the brand awareness; existing marketing activities will be adjusted to respond to expectations (both for productservice specification and "involvement") of the new target group. Step three involves taking a "multidirectional stance" in which an integration and coordination role is established as a central point for new product development and sales by working with upstream (supplier) stakeholders and downstream with end-user customers and intermediaries. In this way every organisation within the value chain network will be able to shift to the most favourable value chain position; the brand cannot be neglected and will be an important part of the end-user experience. Returning to Intel, the brand (the first chip manufacturer) once represented little or no value for most consumers, but now appears prominently on status PC brands as "Intel Inside". This adds value to the PC and is used on their products as a Unique Selling Point. Clearly this cannot be an arbitrary process; some rigorous analysis is required prior to 
identifying and assuming an optimal position. Figure 3 expands Bun and Van Zijll Langhout's proposition in more detail by identifying the underlying issues confronting existing and potential value chain network members

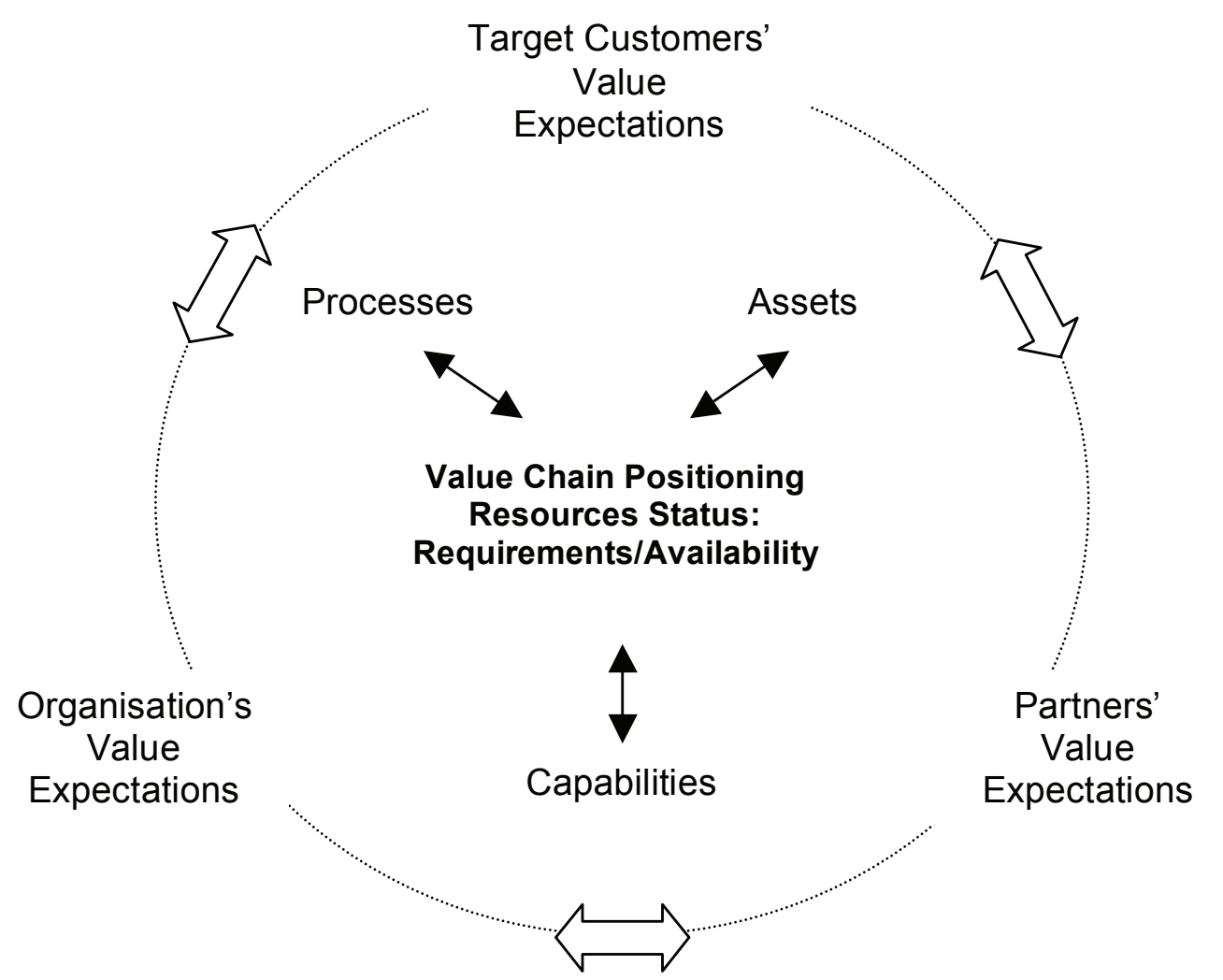

Figure 3: Matching value chain member objectives and resource requirements and availability

Given that the end-customers' expectations have been identified the resources requirements (assets, processes and capabilities) and their availabilities can be assessed. As the value chain network concept is based upon intra- and inter-organisational architecture the task is one of identifying what options are available to the value chain processes (design and development, procurement, etc.) if customer satisfaction is to be realised. It will be recalled that in Figure 2 the proposition made was that an interpreneur typically undertakes an integrating/coordinating role ensuring that the network members show a strategic and an operational "fit"; this may involve managing the entry and exit movements of network members in an attempt to reach an optimal "resource mix". Current thinking in the literature suggests one way of achieving this fit is to use demand chain analysis to create a clear profile of customer expectations and constraints prior to making firm decisions on resource requirements and sources. Thus while Bun and Van Zijll Langhout's proposition suggests that individual organisations identify and "proposition" a target customer segment it is likely that more success (from a value chain network perspective) may be realised if a holistic approach is taken, organised by an interpreneur role. 
An important requirement for all members of the value chain network is that they understand the importance of identifying the all-important customer-facing processes that create the value that in turn creates long-term customer satisfaction. Figure 4 suggests how customerfacing processes can be aligned with value chain network delivery processes.

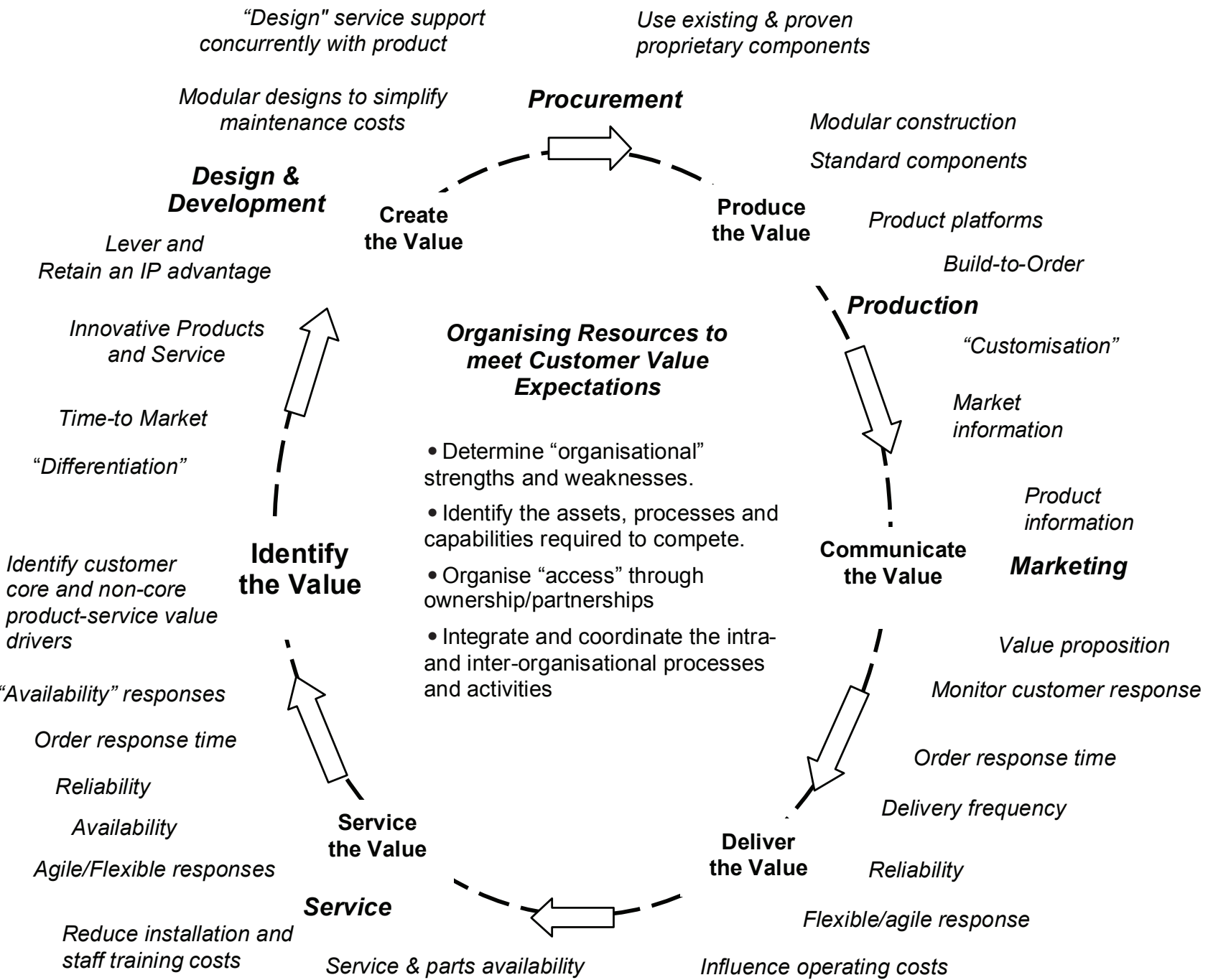

Figure 4: Identifying important customer-facing processes that add customer value

Figure 4 does not consider any specific market. The examples used have been drawn from research undertaken by the author, across a number of product-service offers and markets and clearly it is unlikely they will all be applicable in any one situation. However it does serve to illustrate how a customer response may be built up by researching the processes that have impact a large influence on the key value drivers of the target customer group. Having completed this task Figure 5 illustrates how the result may be applied to a value chain network to create a value proposition. The value proposition is a both a response to the target customer group and a communication to the partner organisations indicating their roles and tasks in the overall task of creating customer satisfaction. Therefore Figure 5 explores a number of the options available for consideration when identifying response processes. 


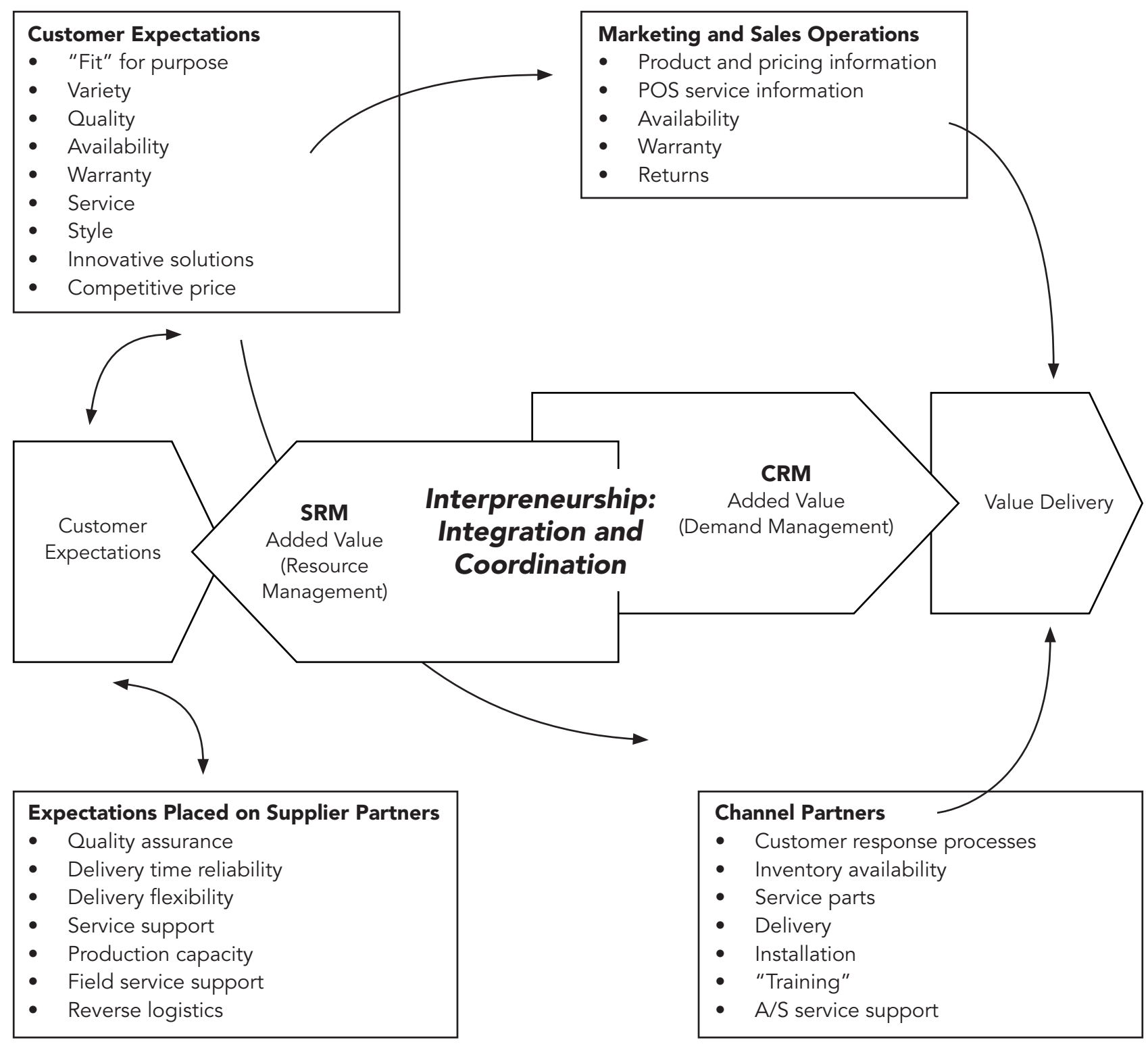

Figure 5: The elements of a value proposition

\section{Value Chain Network (VCN) processes}

It is important to remember that while VCN processes are sequential they typically have separate ownership and are often geographically dispersed. The examples presented earlier are Australian organisations that have distinctive capabilities and focus on specific processes in the VCN and service customers on different continents. That said the following discussion on VCN processes should be read with this in mind. What has accompanied the growth of the VCN has been a sophisticated interactions network.

\section{Research design and development}

Among the many process responses to be considered at the research, development and demonstration (RD\&D) stage probably the most important is relevance of the productservice to customer requirements (customer "fit for purpose"); clearly, unless the value 
proposition is feasible (Walters and Rainbird: 2007) there is no value proposition! Other considerations at the RD\&D stage concern how the roles and tasks may be achieved. Bun and Van Zijll Langhout op cit discuss customer involvement in the design process (cocreativity, prosumerism) suggesting this to be an important feature of the "new business model". There is little doubt that this is so; however, other issues may be equally important. Depending on the importance of specific value drivers it may be necessary to outsource some or all aspects of the RD\&D process. For example Siemens' range of small kitchen appliances (kettles, coffee makers, etc.) have been designed by the Porsche design unit of the automobile company. Often the reseller's value drivers are important; service parts inventories and service tasks need to be considered to ensure inventory holding and servicing activity costs are acceptable. Customer service expectations for service responses, costs and service availability can influence process decisions that include service organisation, skills and locations.

\section{Procurement}

Procurement can play an important role in the value chain. A number of concerns may be addressed by procurement management. Given the value proposition and the RD\&D output procurement may have one of a number of roles. One role is cost control; this does not necessarily imply "lowest possible cost" but more one of sourcing materials and labour to meet quality, lead time, and other customer-led features at a budgeted cost. Hence a number of features influence the procurement task, such as working with RD\&D to develop products that use standard product/industry components (the automobile industry is an example). It may be attractive to join competitors in an industry buying consortia such as "Elemica", a pharmaceutical industry buying organisation. It may involve the organisation in restructuring the business model resulting in a number of partnerships across the industry in which product and process specialisation is important.

\section{Production}

In many ways the "production" process in the value chain network has been influenced more than the other processes as globalisation and process technology have changed the business environment. Global activities have until recently created a number of opportunities. The emerging economies have offered low cost production expertise and these have led to many networks identifying low cost/low tax locations suitable for operations (the very recent trend towards increasing energy costs may result in a rethink of this advantage (Mortishead, 2008). ICT developments (information communications technology) have resulted in alternative, customer-driven, production business models. The traditional "build for inventory" model (BFI) has been replaced by BTO (build to order) and in some target market situations DTO (design to order). These developments have served to enhance customer satisfaction (by increased "fit-for-purpose") and have reduced operating costs (primarily inventory investment costs) by delaying expensive labour inputs. 
"Mass customisation" (providing most customers with most of the product-service features they want, i.e. customised solutions) has led to further production economies with shared product platforms and shared process/flow production systems, "standard components" and "standard processes". Co-productivity models (upstream/downstream process management) as practised by IKEA has seen a number of process innovations in which production processes are moved into value chain network process areas that hitherto had not been involved in the processes. Co-opetition (shared production, sales and distribution facilities) is also becoming a widely adopted model.

\section{Marketing and sales operations}

Working within a value chain network structure places additional tasks on marketing. The traditional tasks of managing demand to achieve market share volumes, to introduce, build and manage the organisation's brands by extension and leverage programmes and possibly franchising remain important. Relationship management becomes an important task as two-way communications with distributors and end-users'me customer contact is essential if customer involvement (prosumerism/co-creativity) in product-service development is important. Another increasingly important role for marketing and sales operations concerns the coordination of promotional activities with sales and logistics management as corporate responsibility for financial performance is shared. Inventory and credit management have a huge impact on working capital productivity. The importance of JIT ("just-in-time") and VMI (Vendor Managed Inventory) programmes places the emphasis of responsibility on sales and logistics operations to ensure that inventory levels are maintained sufficiently high to meet marketing channel needs (and end-customer off-take). This becomes critical for suppliers when dealing with multiple retail organisations many times larger than they are; the relationship between Proctor and Gamble and Wal-Mart is an example - Wal-Mart only pays $P \& G$ for its inventory after it has been sold!

\section{Distribution and service administration}

The maintenance of reliable and accurate service to the customer extends beyond on-time product deliveries. It has become a critical component of customer relationship management because of the role it plays in the customer's own financial performance management tasks. Typically distributors and B2B customers attempt to manage their businesses around tightly controlled cash-flow budgets and are concerned to ensure that their cash-to-cash cycles are coordinated with their own "production" cycles. Therefore it is essential that suppliers manage their order processing, administration and delivery with maximum efficiency.

\section{Customer services management}

Service has become an important feature of an organisation's value proposition. This has occurred for a number of reasons. First, the demand by customers for advice and support throughout a transaction has led to service becoming part of a proactive role in developing a 
problem-solving approach to customer relationships. Secondly, if the organisation is seeking to differentiate its product-service offer it is often more cost-effective to do this through its service component as this may also prove to be a cost-effective way of customising the product-service offer. A third reason is that in B2B markets the cost of customer downtime diminishes the value-in-use of the product - a significant component of the total benefits a supplier is attempting to deliver and clearly the motive for Rolls Royce Aero Engines, Caterpillar and Tandem Computers to use random diagnostics. For some industries service has become a specialist activity. In computing hardware, service organisations manage the warranty and service processes of many of the major hardware manufacturers. Again there are a number of reasons for this to have developed. The growth of IT applications across all industries has been huge and the investment required by the manufacturers to maintain their own service operations would be considerable. This industry, as with other technologybased activities, has resisted what it considers non-core investment. Indeed the computer hardware industry is one in which value migration has been very active throughout all of the value chain processes. Examples were given earlier of ODMs who creatively pull together highly specialised component and subsystem suppliers in order to generate ideas for delivering higher performance at lower cost in a broad range of digital devices, including digital still cameras, mobile telephones, and notebook computers. Instead of designing products in detail from the top down, ODMs specify ambitious performance targets and then rely on this diverse network of technology partners to find new ways of meeting them. It comes as no surprise that this principle is pursued throughout the value chain. It is arguable that HP and Dell are repositioning in the value chain and becoming marketing and selling companies as value migration changes the organisational structures of the successful organisations. Against this background we see the success of companies such as AWA, the Sydney-based computer (and more recently consumer electronics) service organisation.

\section{Logistics and supply management}

Logistics management has become the sophisticated movement of materials/products, information and cash between enterprises. Typically these tasks have required expertise in order cycle management performance, order filling and delivery accuracy, product-service availability (service levels), product-service availability (locations), delivery frequency and delivery reliability, and more recently, reverse logistics processes and their performance. The new business models rely upon logistics management expertise to maintain their efficiency (productivity) as they attempt to offer increasing levels of distribution service (to meet increasing customer demand for service at decreasing costs to meet shareholder and supplier demands for profitability). The trends in both supplier and customer relationship management are for all parties to increase their returns on investment; typically this first involves maintaining service outputs at reduced levels of system inventory and credit. Expansion of business is undertaken with this model firmly in mind - eliminating excesses of both! The recent large and rapid increase in oil prices has led to some strange arithmetic, 
specifically in the relationship to the costs of raw materials and transportation costs and this clearly is a major challenge for logistics management.

\section{Complementors}

Complementors expand existing markets or make new markets accessible. The expansion of consumer credit made a number of markets more accessible; the formation of GM Acceptances made automobile ownership a possibility, not a dream. The move by banking into long-term consumer financing opened up home ownership and with it brought expansion for the residential construction industry, furniture and related product-service markets. Private healthcare expanded as insurance companies developed new product packages and again this was followed by the growth of healthcare services and even hospitals. Travel has benefited from the application of ICT systems following the success of Sabre which created an industry around the capability to link journeys across airlines and into hotel booking systems. In each example we see a systemic synergy combining a group of related activities into a market that while it existed required a catalyst to bring the separate components into a whole entity.

\section{CONCLUDING COMMENTS}

This paper has reviewed some of the recent contributions to the literature on value chain network management. As a concept the value chain is beginning to move away from the misconception that it is simply a supply chain. While there is some conceptual argument concerning the precise nature of the value chain, its customer focus is becoming accepted by authors and, more importantly, by industry practitioners. In this particular paper the argument is made that a thorough understanding of the customer leads to an identification of the market and the industry value chain alternatives that are available to an "organisation" if it is to create a strong relationship with the end-user market. "Organisation" in this context implies an integrated response network (typically a virtually integrated organisation or something in-between such as the Zara organisation that comprises both vertically integrated components with some outsourced processes - virtually integrated partners); the structure that emerges is one that should optimise the returns to all stakeholders.

There is increasing evidence from industry that organisations are aware of the benefits of customer-centricity (identifying specific customer expectations and initiating focused responses) and of the benefits that collaborative value chain networks offer in fulfilling these cost-effectively. Tata, the Indian conglomerate, recently introduced the Nano, a small, low-cost, basic car lacking the features typically taken for granted in vehicles sold in western markets (it has one windshield wiper, narrow wheels and no in-car entertainment). The car will be "produced" by suppliers and distributors using a co-productivity business 
model aimed at maintaining costs at a low level. The vehicle is targeting owners of twowheel vehicles who, if reports of the large interest shown are indicative of sales potential, represent an untapped market segment (Industry Week, 2009).

Panasonic (Wakabayashi: 2009) have announced their EM-WIN programme. EM-WIN is designed to offer a range of Panasonic products to markets in less developed countries. The products will have only the essential features and will be manufactured locally to contain costs. Panasonic argue that they are meeting an identified, local demand, in a realistic manner.

Figure 6 summarises the current approach to the value chain. It can be described as being two networks: vertical and horizontal. The vertical network is an inter-connected series of processes that commence with identifying the expectations of customers and stakeholder partners. These are the basis for structuring a value response that meets these various expectations and attempts to do so while establishing some product-service characteristic(s) that create an advantage over competitive value chain network offers. The horizontal networks are becoming important as the pressure increases on organisations to manage capital investments effectively (strategically) and efficiently (operationally) in what appears to be a time of investment market uncertainty. Competition at a horizontal level between reseller organisations will be supplemented by alternative communication/delivery network systems and collaboration between competitors at all levels of the vertical networks is likely as organisations become "capital lite" and efficient. 
Understand the Value Chain Network, Understand the Market, Understand the Industry and Understand the Customer

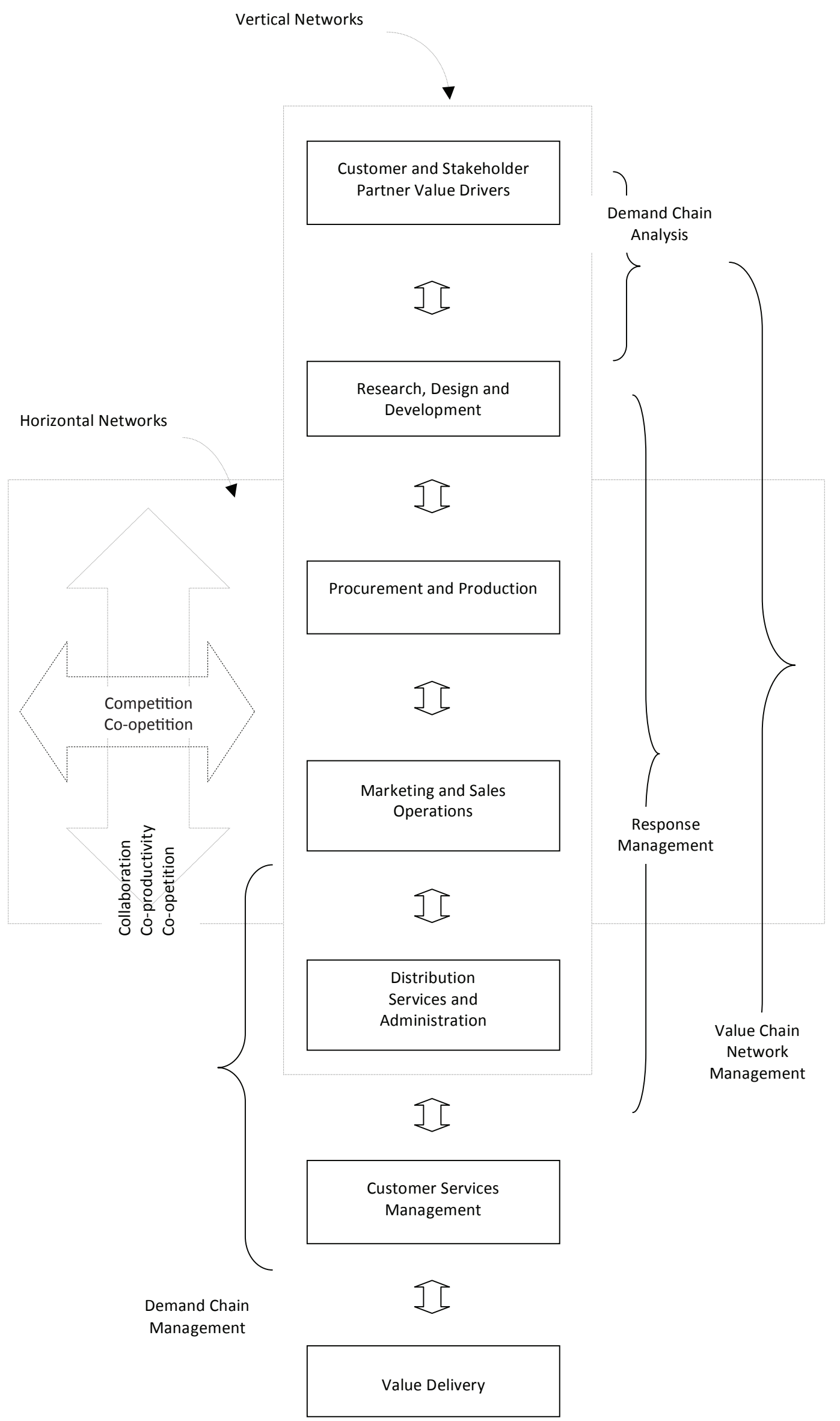

Figure 6: The evolving value chain network 


\section{REFERENCES}

Anderson, J.C. \& Narus, J.A. 1998. Business marketing: understanding what customers value. Harvard Business Review, November/December.

Brown, S. \& Hagell III, J. 2005. From push to pull: The next frontier of innovation. McKinsey Quarterly, Number 3.

Bun, E. \& Van Zijll Langhout, J. 2008. www.shakingupthevaluechain.com.

Champy, J. 2008. Outsmart, Pearson Education/FTPress, NJ.

Flint, D. 2008. Moving value through the supply chain. Industry Week. 4 August.

Godsell, J., Harrison, A., Emberson, C. \& Storey, J. 2006. Customer responsive supply chain strategy: An unnatural act? International Journal of Logistics, 9(1). March.

Grey, B. 2006. IMS (Intelligent Manufacturing Systems). Vision Forum.

Heskett, J.L., Sasser Jr. W.E. \& Schlesinger, L.A. 1997. The service profit chain. The Free Press, NY.

Industry Week, Anonymous. 2009. Tata Will Launch Nano Car Next Month. 26 February.

Jay, C. 2008. Linking into world growth through a value supply chain. The Australian Financial Review. 25 July.

Lloyd, G. 2007. Smart factories defy strong dollar, Chinese imports. The Australian. 9/10 June.

MacMillan, I.C. \& McGrath, R.G. 1997. Discovering new points of differentiation. Harvard Business Review. July/August.

Mentzer, J.T. 2006. A telling fortune. Industrial Engineer. April.

Mortishead, C. 2008. Rising transport costs hammer globalisation. The Times, London (reproduced in The Australian, 12 June).

Parasuraman, A.V., Zeithaml, A. \& Berry, L. 1985. A conceptual model of service quality and its implications for future research. Journal of Marketing, 49(4).

Roberts, J. 2004. The Modern Firm. OUP, New York. 
Slywotzky, A.J. \& Morrison, D.J. 1997. The Profit Zone, Wiley, New York.

Stank, T. \& Mentzer, J. 2007. demand and supply integration: a key to improved firm performance. Industry Week Value Chain eNewsletter. 17 December.

Tierney, S. 2003. Tune up for a super-efficient supply chain with a Triangle. Frontline Solutions (Pan-European edition), Duluth. Jun 2003.

Vatne, E. 1995. Local resource mobilisation and internationalisation strategies in small and medium sized enterprises. Environment and Planning A. 27(1).

Wakabayashi, D. 2009. Panasonic downsizes product design and price to fit emerging markets. The Australia/Wall Street Journal. 10 July.

Walters, D. \& Rainbird, M. 2007. Strategic Operations Management: a Value Chain Approach, Palgrave/Macmillan, Basingstoke, UK. 